\title{
Intimate partner violence and its association with self- determination needs and gender-power constructs among rural South African women
}

Citation for published version (APA):

Mpondo, F., Ruiter, R. A. C., van den Borne, B., \& Reddy, P. S. (2019). Intimate partner violence and its association with self-determination needs and gender-power constructs among rural South African women. Journal of Interpersonal Violence, 34(14), 2975-2995. https://doi.org/10.1177/0886260516664316

Document status and date:

Published: 01/07/2019

DOI:

10.1177/0886260516664316

Document Version:

Accepted author manuscript (Peer reviewed / editorial board version)

Please check the document version of this publication:

- A submitted manuscript is the version of the article upon submission and before peer-review. There can be important differences between the submitted version and the official published version of record.

People interested in the research are advised to contact the author for the final version of the publication, or visit the DOI to the publisher's website.

- The final author version and the galley proof are versions of the publication after peer review.

- The final published version features the final layout of the paper including the volume, issue and page numbers.

Link to publication

\footnotetext{
General rights rights.

- You may freely distribute the URL identifying the publication in the public portal. please follow below link for the End User Agreement:

www.umlib.nl/taverne-license

Take down policy

If you believe that this document breaches copyright please contact us at:

repository@maastrichtuniversity.nl

providing details and we will investigate your claim.
}

Copyright and moral rights for the publications made accessible in the public portal are retained by the authors and/or other copyright owners and it is a condition of accessing publications that users recognise and abide by the legal requirements associated with these

- Users may download and print one copy of any publication from the public portal for the purpose of private study or research.

- You may not further distribute the material or use it for any profit-making activity or commercial gain

If the publication is distributed under the terms of Article $25 \mathrm{fa}$ of the Dutch Copyright Act, indicated by the "Taverne" license above, 
Intimate partner violence and its association with self-determination needs and gender-power constructs amongst rural South African women

\begin{abstract}
Author note
Feziwe Mpondo, Department of Work and Social Psychology, Maastricht University;

Robert A. C. Ruiter, Department of Work and Social Psychology, Maastricht University;

Dilana Schaafsma, Fontys Eindhoven; Bart van den Borne, CAPHRI School of Public

Health and Primary Care, Maastricht University; Priscilla S. Reddy, Population Health, Systems and Innovation, Human Sciences Research Council, South Africa, Child and

Family Studies, Social Work Department, Community and Health Sciences, University of the Western Cape
\end{abstract}

Corresponding author:

Feziwe Mpondo -mailto:feziwe.mpondo@maastrichtuniversity.nl 


\section{Abstract}

This study aimed to identify psychosocial correlates of intimate partner violence (IPV) by using constructs derived from the self-determination theory (SDT) and genderpower scales. Cross-sectional data $(\mathrm{N}=238)$ were collected from women in the Eastern Cape, South Africa and were used to test a structural equation model (SEM). The majority (87\%) of the participants reported having sexual partners in the past 3 months, and in terms of IPV victimization $36 \%$ and $26 \%$ of women had ever experienced verbal and physical abuse, respectively. Bivariate correlations showed that autonomy and beliefs about gender equality (BGE) were strongly associated with IPV. This finding was also confirmed in the SEM analysis, which indicated that autonomy had a direct effect on IPV suggesting that women who are in relationships that allow them to make decisions along with their partners possibly experience less intimate partner violence. In addition BGE, which was hypothesized to play a mediating role showed a significant direct association with IPV, suggesting that women who are aware of their rights may experience less IPV by choosing partners who do not espouse hegemonic masculinities or strong patriarchal beliefs. Our findings suggest that it would be important to incorporate decision-making skills and human rights awareness in future community-based sexual health and reproductive rights interventions.

Key words: intimate partner violence, self-determination, gender equality beliefs, young women 


\section{Introduction}

Researchers and policy makers from around the globe have made a concerted effort into getting intimate partner violence (IPV) recognized as a serious public health problem which has devastating outcomes for many societies (Grose and Grabe, 2014; Russell et al., 2014; van Niekerk and Boonzaier, 2014; Stöckl et al., 2015). South Africa is one of the highest-ranking countries in IPV prevalence, where 20-50\% of everpartnered adult women have reported ever experiencing physical, sexual or emotional violence (Abrahams et al, 2014; Shai and Sikweyiya, 2015; Devries et al., 2013). In the last two decades South African researchers, health practitioners and activists have initiated and conducted work to mobilize communities and to develop solutions for addressing IPV (Abrahams et al., 2014; Jewkes, 2002; Meintjes, 2003; Kim et al., 2007; Jewkes et al., 2010, Seedat et al., 2009). There have been some positive effects, for example, the government previously labelled intimate partner violence as a private matter not needing any specific interventions; now IPV is recognized as a punishable criminal offence (Meintjes, 2003; Domestic Violence Act 116, 1998; Seedat et al., 2009; Mogale et al., 2012). However, the surface has barely been scratched, as South Africa still remains one of the highest-ranking countries in IPV prevalence.

This paper investigates correlates of intimate partner violence amongst young South African rural women. Earlier research focused on investigating personal and interpersonal factors associated with IPV, where it was shown that women who have poor education and low or no income tend to be more vulnerable to violent sexual relationships (Jewkes, 2002; Dunkle et al., 2004; Abrahams et al., 2004). In addition, alcohol or substance use by women or their partners predisposes women to intimate 
partner violence (Dunkle et al., 2004; Abrahams et al., 2004; Gass et al., 2011; Abramsky et al., 2011). The research into personal and interpersonal risk factors of IPV has been important and useful in helping identify subgroups that are susceptible to violence.

However, these factors do not fully explain the underlying factors that drive, maintain or increase IPV. In order to fully understand the drivers we have to first understand the context within which violence occurs. Theories at different ecological levels are good instruments that can help us achieve this goal by enabling us to consider the interactions of personal, family, community and social factors and how these influence interpersonal relationships, and in turn how that influence contributes to victimization and perpetration of violence (Koenig et al., 2003; Bell and Naugle, 2008; Cavanaugh, Hansen and Sullivan 2010; Ali and Naylor, 2013).

In this study we used self-determination theory (SDT) with the aim of identifying psychosocial factors that contribute to women's exposure to or protection against IPV. SDT hypothesizes that human beings have three psychological needs namely competence, autonomy, and relatedness, which have to be met in order for individuals to have good health outcomes. When the three SDT needs are met individuals gain psychological strength to start and maintain healthier behavior (Silva et al., 2014). The autonomy need is described as a fundamental human need; it provides an environment that enables freedom and agency in life situations. This means that decision-making in sexual relationships is experienced or understood as an exercise where both partners willingly participate. This is mainly determined by whether or not both partners cultivate autonomy. The autonomy need being described here is distinct from the concepts of individualism, independence, and separateness. Also, autonomy should not be understood 
as being the opposite of dependence; it should rather be understood as being the opposite of heterenomy - a concept where an individual is forced to adopt decisions, in this case by a sexual partner, despite strongly holding different views or interests (Chirkov et al., 2003). Competence involves feeling effective in ongoing interactions with one's external environment; it also forms the foundation for self-esteem and self-confidence (Sheldon et al., 1996; Ng et al., 2012). The competence need is also linked to one’s control of motivations, where an individual is able to plan and strategize on different routes needed to progress towards a goal (Ng et al., 2012; Patrick et al., 2007). Relatedness can be defined as feeling connected to a partner, feeling secure, having a sense of belonging with others, in a social environment (Weinstein and Ryan, 2011; Patrick et al., 2007). The three psychological needs in life situations where wellbeing is promoted have been shown to enable freedom and agency. Moreover, these needs being met means that decisions and beliefs are internalized and therefore will be sustained in the long term (Weinstein and Ryan, 2011; Patrick et al., 2007). Therefore it is important to investigate whether women who feel autonomous, competent or efficacious in enacting safe sexual behaviors, and who feel connected to their partners and their social networks are protected against IPV.

In addition, gender-power ideologies at interpersonal and community levels were also considered because research shows that gender relations play an important role in the exposure or perpetration of IPV (Pettifor et al., 2012; Morrell et al., 2012; Gibbs et al., 2014; Shefer et al., 2008). IPV thrives in societies that are organized along patriarchal lines and South Africa is an example of such a society. Even though the constitution recognizes equal and inalienable human rights for males and females, as well as the 
representation of women in politics and in education, the recognition of these rights is yet to translate to social spaces (Bill of rights, South Africa; Section 9(4), 1996). Women continue to be in social positions that are insecure as is evidenced by the lack of socioeconomic resources and not having a voice in many local and traditional matters, especially in rural communities (Walker and Barton, 2013; Albertyn, 2011). In environments where experiences of manhood and womanhood are dictated by oppressive and very conservative traditions, power shifts to men and norms that valorize hegemonic masculinities are promoted. The promotion of hegemonic masculinities is characterized by placing value on physical strength, aggression, control of female partner, expression of virility, male entitlement, and gender inequitable attitudes (Pettifor et al., 2012; Albertyn, 2011; Walker and Barton, 2013). Women on the other hand are expected to be demure and acquiescing especially in sexual relationships (Pettifor et al., 2012; Albertyn, 2011; Walker and Barton, 2013). Also such societies are often restrictive and punitive on women to such an extent that when women are victims of interpersonal violence in sexual relationships they often do not challenge their situation nor report it. Instead they live in fear or they just try to cope because IPV is often still branded a private matter in South African communities (Shai and Skweyiya, 2015). In this study we wanted to understand whether rural women internalize negative or positive gender ideologies (power and violence beliefs) and if so what associations does that have with women’s IPV victimization or absence thereof.

We hypothesized that the three psychological needs constructs- autonomy, competence and relatedness would associated with young women's victimization to IPV and that gender-power constructs would mediate the association of the three needs with 
IPV. Gender-power constructs were hypothesized to play a mediating role because they are understood to be representing the underlying socio-cultural mechanisms that explain how an individual's feelings of autonomy, competence and relatedness influences whether or not they get exposed to IPV. This means that women's beliefs about gender power issues depend on how empowered they are, and these beliefs in turn are important in the choice of partners and thus the chances of being exposed to IPV.

\section{Methods}

\section{Study setting and sampling}

This paper reports on a component of baseline data that were collected as part of a randomized controlled trial (Mpondo et al., 2015). From September 2012 to March 2013 participants were recruited from the OR Tambo and Amathole district municipalities of the Eastern Cape Province, South Africa; both districts lie along the Eastern seaboard of the Indian Ocean. Women were recruited through an extension network of the Eastern Cape Royal Chiefs’ [Imbumba Yoomama Bakomkhulu/IYA] wives a local tribal authority and development organization. IYA members recruited local women for the study through using the word of mouth in community structures. Community research assistants (CRAs) then contacted those women via telephone for screening, and to set baseline assessment interview appointments. Participants were eligible if they were between 18 to 35 years of age, had low levels of education (below South African Senior certificate), were Xhosa speaking, were unemployed at entry of study, and were not pregnant. The selection criteria were established from the needs analysis conducted prior to baseline data collection, where the profile of women exposed to adverse physical 
(particularly sexual risk) and psychological health was developed. A total of 270 eligible women were sampled and of those 238 completed the questionnaire. The remainder did not meet the inclusion criteria due to one of the following reasons: possible relocation plans, reporting of mental illness, not attending appointments for the baseline assessment, and refusing participation.

\section{Procedure}

Data were collected by six trained isiXhosa-speaking, female community research assistants (CRAs). The CRAs were familiarized with the objectives of the study, trained on how to recruit participants, obtain informed consent, and administer the questionnaire. All questionnaires were administered in isiXhosa through face-to-face interviews. The assessments were carried out at the local tribal authority homesteads because these were centrally located and accessible to all participants. Prior to conducting interviews participants were verbally informed about the content of the study, procedures, and confidentiality. At the end of the information session written consent was obtained from each participant. Ethical approval was obtained from the Walter Sisulu University BioEthics Committee.

\section{Measures and scale construction}

The primary questionnaire was developed in English and then translated to isiXhosa for comprehension, cultural applicability and language appropriateness, and subsequently back translated to English to check for accuracy, and finally pretested on Xhosa-speaking women. 


\section{Socio-demographic variables}

Socio-demographic variables included age, highest grade passed $(1=$ no schooling to primary schooling, 2 = secondary schooling and 3 = Post matric), marital status (dichotomised to $1=$ married and 2= not married). Employment status of the participant and their partner (categorized as unemployed, disabled, social grant, employed less than 5 days or employed more than 5 days) as well as household income in South African Rand were assessed (see also Table 1).

\section{Sexual behavior}

The sexual behavior question assessed whether a person had a sexual primary partner $(0=$ No, $1=$ Yes $)$ and a secondary $/$ casual partner $(0=$ No, $1=$ Yes $)$. One openended question asked about the number of men a participant had sex with in the past 3months. Another open ended question asked "How old is the person you last had sex with”.

\section{Measures}

For the measures below confirmatory factor analysis was conducted using SPSS version 22 (SPSS Inc., Chicago, IL) as pre-analysis and to check whether items indeed grouped together as would be expected. Scree plots and principal axis factor analysis and direct oblimin rotations were used for extracting factors. Items with factor loadings of .40 or higher were grouped and subjected to reliability analysis. Groups of items with a Cronbach's alpha $[\alpha]$ score of .60 or higher were averaged into a single construct and labelled to reflect the underlying variable that was measured. All measures were based on Likert-type items, unless otherwise indicated. Items and variables were recoded such that higher scores reflect a stronger presence of the pertinent variable. 


\section{Intimate partner violence measures}

Intimate partner violence was assessed with a 5-item scale which focused on physical and verbal abuse, the response options were from $0=$ never to $3=$ always (i.e., “Does your partner ever yell or curse at you?”, “Does your partner ever threaten to leave you?”, “Does your partner ever threaten to hit you?”, “Has your partner ever hit you?”, “Did your partner ever leave you?”; $\alpha=.80)$. Intimate partner violence served as the main outcome measure for this study.

Beliefs about intimate partner violence were assessed with a 4-item scale with response options from $1=$ strongly agree to $5=$ strongly disagree. The scale was assessed with the following questions: “There are times when a woman deserves to be beaten”, "If a woman insults her man, he should defend his reputation with force”, “A man using violence against his wife is a private matter that should be discussed only by the couple”, and “A woman should tolerate violence to keep her family together" $(\alpha=.60)$. A higher score reflected more negative beliefs towards intimate partner violence. Intimate partner violence and beliefs about intimate partner violence were both taken from the Compendium of Gender Scales (Nanda, 2011).

\section{Three SDT psychological needs}

We operationalized the three SDT psychological needs (autonomy, competence and relatedness) by using measures that we theoretically and conceptually linked to each of the needs respectively. Autonomy was assessed with a measure of attitude towards decision-making, competence with a measure of self-efficacy to practice safe sex, and relatedness was measured with an interpersonal support sub-scale. Attitude towards decision-making was measured with a 6-item scale with response options $1=$ strongly 
disagree to 5 = strongly agree obtained from the Compendium of Gender Scales (Nanda, 2011). Example items are "No one should have more power than the other in a relationship” and "My partner and I sit down and discuss important matters” $(\alpha=.70)$. A higher score reflected more positive attitudes towards equal decision making in a sexual relationship.

Self-efficacy to practice safe sex was measured with a 6-item scale with answering options from 1 = strongly agree to 4= strongly disagree (Brafford and Beck, 1991) with items such as "I am certain I know how to use a condom correctly" and "I am confident that I can have safe sex and satisfy my partner” $(\alpha=.80)$. Scores were coded such that higher scores reflect more self-efficacy to practice safe sex.

Interpersonal support was measured with a 28-item scale with scoring options $0=$ definitely false to 3 = definitely true) (Brookings and Bolton, 1988). Factor analysis showed a two-factor solution, presence of support (e.g., "If I were sick I could easily find someone to help me with my daily activities” with a total of 11 items, 3 items were dropped after reliability analysis, $\alpha=.74$ ) and lack of support (e.g., "If a family crises arose, it would be difficult to find someone who could give me good advice about how to handle it” with a total of 14 items; $\alpha=.72$ ). In our analysis presence of support was used because it best captured the concept of relatedness with higher scores reflecting more presence of support.

\section{Beliefs about gender equality}

Beliefs about gender equality were measured with a 4-item scale with response options 1 = strongly agree to 5 = strongly disagree: "If both of us are working, the husband should do the same amount of chores as the wife”, "I believe a woman's place is 
in the home”, "In our family, as a wife I should not work outside unless it is a financial necessity”, “The husband should have the final word in most of the important decisions in our family”. After re-coding, a higher score reflected having more positive beliefs towards gender equality $(\alpha=.60)$.

\section{Model development and analysis}

A step-wise structural equation modelling (SEM) was conducted using MPlus version 7.11 (Muthén and Muthén, 2013) to assess the fitness of the proposed conceptual model. First, confirmatory factor analysis (CFA) was conducted with the aim of testing or confirming SPSS results (Byrne \& Stewart, 2006). All measures were confirmed to be one factor constructs except for the presence of support (relatedness) and self-efficacy to practice safe sex (competence), which were shown to each have two factors. For presence of support the factor with 4 items was used, and for self-efficacy to use a condom a factor with 3-items was used for further analysis. The other factors for both measures were dropped to improve model fit. In the next step a measurement model was fitted with all latent variables tested as $2^{\text {nd }}$ order factors. A maximum likelihood estimator (MLR) was used to account for the fact that there were some missing data points; about $1.3-4.4 \%$ data points were missing for the respective measures used in this analysis. The MLR estimator uses standard errors and a chi-square test statistic that is robust to non-normality (Yuan Bentley Chi-square).

Subsequently a full structural model based on the theoretical conceptual model was specified. The sample $(n=238)$ was used for both the measurement and structural models and even though it was relatively small it allowed for a well-specified model to be tested (Jackson, 2001). The following statistics were used to assess an adequate 
structural model fit, such as the comparative fit index (CFI) (Bentler, 1990), the root mean square root error of approximation (RMSEA) (Steiger, 1990), and a standardized root mean square residual (SRMR). A CFI that is $\geq .90$ or, $\geq .95$; RMSEA must be $\leq .08$ or $\leq .05$ and SRMR should be $\leq .08$ (Hu \& Bentler, 1999). Furthermore indirect effects from the structural model were tested using bootstrapped standard errors $(n=5000)$ to construct 95\% confidence intervals.

\section{Results}

\section{Demographic profile of participants}

A total of 238 women were interviewed at baseline of the study. The mean age of those women was 25.9 years (standard deviation $(\mathrm{SD})=4.37$ ) with the youngest being 18 years and the oldest 35 years. All participants were Xhosa speaking. Other sociodemographic characteristics are included in Table 1. 
Table1. Socio-demographic profile of sampled women living in rural communities in the Eastern Cape ( $\mathrm{N}=238)$.

\begin{tabular}{lll}
\hline Variables & Frequency (Cumulative\%) & Percentage (\%) \\
\hline Education level & & \\
No formal Schooling & $1(0.4)$ & 0.5 \\
Primary school & $8(3.4)$ & 3.7 \\
Secondary school & $164(68.9)$ & 76.3 \\
Other & $42(17.6)$ & 19.5 \\
& & \\
Marital status & $25(10.5)$ & 10.6 \\
Married & $208(88.2)$ & 89.4 \\
Not Married & $77(32.4)$ & 32.4 \\
Have 1 or more children (Yes) & $161(67.7)$ & 67.7 \\
Have 1 or more children (No) & & \\
& & \\
Employment Status & $0(0)$ & 0 \\
More than 5days & $5(2.1)$ & 2.1 \\
Less than 5 days & $51(21.4)$ & 21.8 \\
Social grant & $17(7.1)$ & 7.3 \\
Stay at home & $1(0.4)$ & 0.4 \\
Ill/Disabled & $158(67.2)$ & 68.4 \\
Unemployed & & \\
Partner's Employment Status & $15(6.7)$ & 7.0 \\
More than 5days & $8(3.4)$ & 3.7 \\
Less than 5 days & $15(6.3)$ & 7.0 \\
Social grant & $22(9.2)$ & 10.3 \\
Stay at home & $6(2.5)$ & 2.8 \\
Ill/Disabled & $148(62.2)$ & 69.1 \\
Unemployed & & \\
& $52(21.8)$ & 22.5 \\
Household Income & $168(71.5)$ & 73.6 \\
No Income & $12(3.7)$ & 3.8 \\
Under 10000 & & \\
Over 10000 & & \\
\hline
\end{tabular}

\section{Sexual behaviors and intimate violence exposure}

About 66 percent of the participants in the study reported having a partner (main or casual). The majority (87.4\%) of the participants reported having had sex with one partner in the last 3 months, while 9.7\% reported having had more than one sexual partner in the same 3-month period. A minority of the participants (39.4\%) reported using condoms at last sex and $11.2 \%$ reported ever having had a sexually transmitted infection (STI). The mean age of the participants' sexual partners was 30 years $(\mathrm{SD}=6.00)$ with the youngest partner being 18 years and the oldest being 49 years. About $12.7 \%$ of the 
young women reported having a sexual partner who was 36 years and older. In terms of victimization about $36 \%$ of participants had been verbally abused by their partner. About a quarter (26\%) of the participants were physically abused (beaten or hit) by their sexual partners.

\section{Bivariate correlations}

Inter-item correlations are presented in Table 2. In terms of effect sizes, weak associations are correlations with Pearson $r$ between.10-.23; a correlation between .24-.36 shows an association of moderate strength, and a correlation of $r \geq .37$ indicates a strong association (Cohen, 1988). The bivariate correlation analysis showed that beliefs about gender equality (BGE), autonomy and relatedness were negatively associated with IPV representing weak associations. Beliefs about partner violence (BPV) and competence were not significantly associated with IPV. In addition, BPV was positively associated with competence representing a moderate association. Autonomy and relatedness were negatively associated with BGE representing weak to medium associations. Competence and relatedness showed moderate positive associations with autonomy.

Table2: Correlation matrix of the latent variables for the structural equation model

\begin{tabular}{lllllll}
\hline Measure & 1. & 2. & 3. & 4. & 5. & 6. \\
\hline 1. IPV & - & & & & & \\
2. BPV & -.07 & - & & & & \\
3. BGE & $-.19^{\mathrm{b}}$ & .05 & - & & & \\
4.Autonomy & $-.21^{\mathrm{b}}$ & .08 & $-.16^{\mathrm{b}}$ & - & & \\
5. Com_S & -.07 & $.27^{\mathrm{b}}$ & $.18^{\mathrm{b}}$ & $.36^{\mathrm{b}}$ & - & \\
6.Relatedness & $-.19^{\mathrm{b}}$ & -.03 & $-.29^{\mathrm{b}}$ & $.25^{\mathrm{b}}$ & $.14^{\mathrm{a}}$ & - \\
\hline
\end{tabular}

a $p<.05 \mathrm{~b} p<.01$

IPV = intimate partner violence; BPV= beliefs about partner violence; $\mathrm{BGE}=$ beliefs about gender equality; Autonomy= operationalized with attitudes towards decision-making, Com_S = Competence operationalized with self-efficacy to practice safe sex, Relatedness = operationalized with presence of support. 


\section{Measurement Model}

The results of the CFA analysis and the hypothesized measurement model with all factors structures are presented in Table 3. The hypothesized conceptual measurement model fit was just adequate $\left(\mathrm{X}^{2}=379.037 ; d f=307 \mathrm{p}<.001 ; \mathrm{CFI}=0.947 ; \mathrm{TLI}=0.929\right.$; RMSEA $=0.038 ;$ SRMR $=0.05 \mathrm{p}<.05)$. To improve the fit, single items from BGE and BPV were dropped, as they did not fit well with their constructs (low factor loadings) (Brown, 2015). The fit for the complete measurement model improved $\left(\mathrm{X}^{2}=307.194 ; d f\right.$ $=237 \mathrm{p}<.001 ; \mathrm{CFI}=0.939 ; \mathrm{TLI}=0.929 ; \mathrm{RMSEA}=0.035 ; \mathrm{SRMR}=0.05 \mathrm{p}<.05)$.

Table3: Model fit statistics for the confirmatory factor analysis

\begin{tabular}{|c|c|c|c|c|c|c|c|c|}
\hline Measure & Model & Observed & YB- $\boldsymbol{X}^{2}$ & $d f$ & CFI & $T L I$ & RMSEA & SRMR \\
\hline Com_S & Competence & 3 & 0.000 & 0 & 1.000 & 1.000 & 0.00 & 0.00 \\
\hline Relatedness & Relatedness & 4 & 3.155 & 2 & 0.980 & 0.941 & 0.05 & 0.03 \\
\hline $\begin{array}{l}\text { Attitudes towards } \\
\text { decision making }\end{array}$ & Autonomy & 6 & 19.076 & 9 & 0.940 & 0.901 & 0.07 & 0.05 \\
\hline $\begin{array}{l}\text { Intimate partner } \\
\text { violence }\end{array}$ & IPV & 5 & 4.978 & 5 & 1.000 & 1.000 & 0.00 & 0.02 \\
\hline $\begin{array}{l}\text { Beliefs about } \\
\text { partner violence }\end{array}$ & BPV & 3 & 0.000 & 0 & 1.000 & 1.000 & 0.00 & 0.00 \\
\hline $\begin{array}{l}\text { Beliefs about } \\
\text { gender equality }\end{array}$ & BGE & 3 & 0.000 & 0 & 1.000 & 1.000 & 0.00 & 0.00 \\
\hline All & Complete model & 24 & 307.194 & 237 & 0.939 & 0.929 & 0.035 & 0.05 \\
\hline
\end{tabular}

Observed=variable count. YB-X ${ }^{2}=$ Yuan-Bentler rescaled; $\mathrm{df}=$ degrees of freedom; CFI = comparative fit index; TLI= Tucker Lewis Index; RMSEA = root mean squared error of approximation; SRMR = standardized root mean squared residual. 


\section{Structural Model}

Figure 1 depicts the results of the hypothesized structural model, which highlights the relations of the latent variables. The significant paths are indicated with bold arrows, the corresponding factor loadings are also indicated for all the paths. The fit of the final structural model was good $\left(\mathrm{X}^{2}=313.980 ; d f=239 \mathrm{p}<.001 ; \mathrm{CFI}=0.935 ; \mathrm{TLI}=0.925\right.$; RMSEA $=0.036$; SRMR $=0.06 \mathrm{p}<.05$ ). In terms of the direct effects, the autonomy to IPV path was significant and negative (standardized structural coefficient $=-.24 ; \mathrm{p}=.01$ ) suggesting that women who felt autonomous in their sexual relationships may have experienced less IPV victimization. The relatedness path to IPV showed a tendency towards significance (standardized structural coefficient $=-.19 ; \mathrm{p}=.10$ ), whereas competence showed no significant association with the outcome variable (IPV). The results of the hypothesized indirect paths were analysed according to the empirical conditions of mediation (Baron and Kenny, 1986). A significant negative direct path from BGE to IPV (standardized structural coefficient $=-.26 ; \mathrm{p}=.02$ ) was observed, the competence to BGE path was also significant with a positive association (standardized structural coefficient $=.28 ; \mathrm{p}=.02$ ). The results described above suggest that BGE is a full mediator of the competence and IPV path. The hypothesized indirect path of autonomy to IPV through BGE only showed a tendency towards significance (standardized structural coefficient $=-.21 ; \mathrm{p}=.08$ ) while the direct path from autonomy to IPV was significant therefore suggesting that BGE was not a mediator between autonomy and IPV. The relatedness (indirect) path through BGE also only showed a tendency towards significance (standardized structural coefficient $=-.21 ; \mathrm{p}=.10$ ) suggesting that there was no mediation through this path either. The observed indirect 
path of competence to IPV was subjected to MPlus test for mediation to verify whether indeed there was mediation, however, the test yielded no significant statistical results $(\mathrm{z}=$ -1.113; $\mathrm{p}=.30$ ). No significance was observed for the hypothesized indirect path between competence, BPV and IPV thus suggesting that even though the path from competence to $\mathrm{BPV}$ was significant (standardized structural coefficient $=.28 ; \mathrm{p}=.00$ ), $\mathrm{BPV}$ in turn did not relate to IPV. 


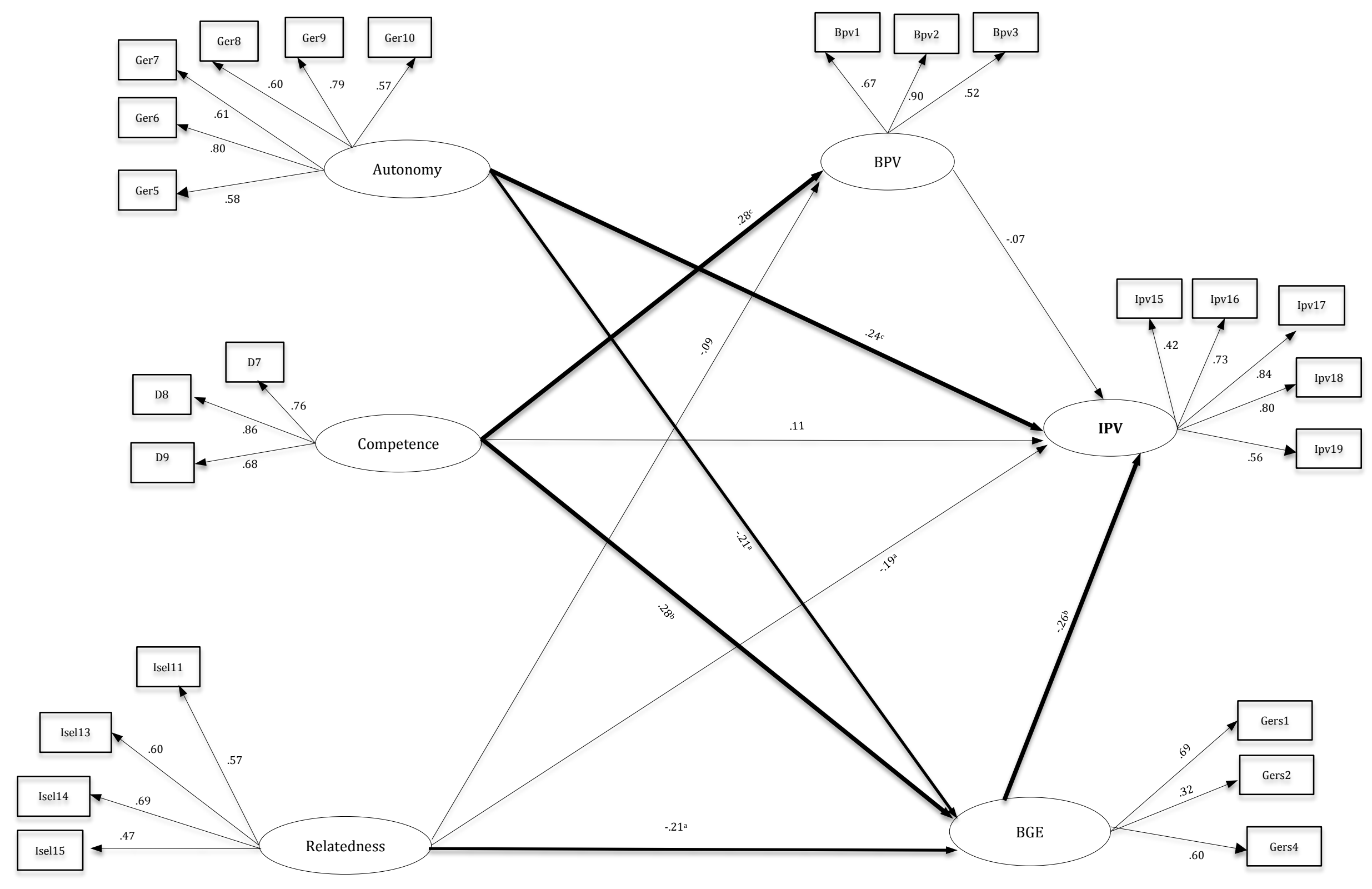

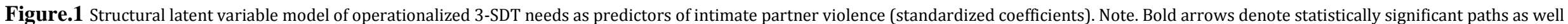

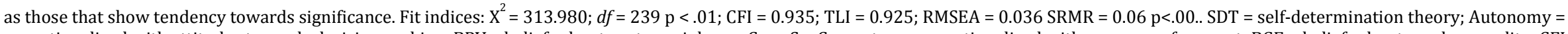

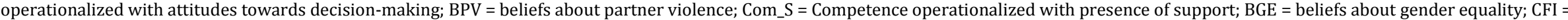
comparative fit index; TLI = Tucker-Lewis Index; RMSEA = root squared error of approximation; SRMR = standardized root mean squared residual. Labels= ${ }^{a}<<.10$; ${ }^{b}<<.05$; ${ }^{c} p<.01$ 


\section{Discussion}

More than a quarter of young women (18-35 years) in our study reported having experienced verbal or physical violence by their sexual partners in their most recent relationships. This finding highlights the persisting problem in sexual relationships amongst South African young women (Shai and Sikweyiya, 2015; Devries et al., 2013). The reported verbal or physical violence, which may even have been underreported here, and the reports of inconsistent condom use (only $40 \%$ of women said that they used condoms at last sex) indicate that women continue to be exposed to adverse health conditions. Especially since previous studies have shown that violence and lack of condom use are strongly linked to the risk of HIV infection (Decker et al., 2014; Karamagi et al., 2006).

Bivariate analyses showed that autonomy and relatedness had significant associations with IPV. Of these two latent variables autonomy was shown to have a significant direct association with IPV in the structural equation modelling as well, whereas relatedness was not shown to have a direct effect on the outcome variable. Autonomy being negatively associated with IPV may mean that women who feel a sense of agency or who feel included or consulted by their partners in decision-making within sexual relationships are less likely to be exposed to verbal physical and sexual violence possibly because joint decision making acknowledges each partner’s values and cultivates trust in a sexual relationship and as such the male partner will be less likely to assert himself through violence (Minnis et al., 2015; Ogland et al., 2014).

BGE did not mediate the effect of autonomy on IPV. But, the fact that it has a significant negative direct association with IPV is important, suggesting that women who 
hold gender equality beliefs may involve themselves less in oppressive relationships and thus get exposed less to violence (DePadilla et al., 2011; Wingood, Cooper, \&

DiClemente, 2011; Wingood et al., 2013). They may choose partners who do not espouse hegemonic masculinities as those partners that do may be perceived as violent. Further, the association also highlights the importance of including human rights in interventions, especially how these rights can be practiced or applied in personal situations. These interventions should help women understand that relationships that recognize equality of partners are healthier than those that do not, and it would be important to promote autonomy and competence feelings for healthier (sexual) relationships.

The indirect path of competence to IPV via BGE needs further investigation, as it was shown to be significant in the structural equation model but not proven to be so in the mediation analysis possibly due to power issues as our sample was relatively small. Further, competence being positively associated with BGE suggests that women who are efficacious in practicing safe sex or suggesting condom use also have an ability to choose healthier relationships and therefore may experience less violence (DePadilla et al., 2011; Wingood et al., 2013). Even though in the structural model BGE was also not shown to mediate the path between autonomy and IPV, it is important to understand the relationship between autonomy and BGE as the concept of equality is proximal to having the need for autonomy met. Further research may help us better understand the association between these concepts.

Also further research is needed to better understand the significant negative bivariate association between BGE and relatedness that approached significance in the structural model. Past research shows that in cases where social support was not present, 
women where shown to be more likely to suffer from mental ill health (stress and depression) and in worst cases psychiatric morbidity (Coker et al., 2002). Beyond sharing challenges about sexual relationships, social networks are used for practical purposes such as poverty alleviation especially since unemployment is so rife in rural communities. It would be interesting to understand what role relatedness plays in preventing women from being involved in violent relationships, especialy in a patriarchal context such as the one where our study was conducted.

We conclude that this study supports the SDT theory by showing that autonomy (direct effect) and competence (indirectly through BGE) measures are associated with less exposure to verbal and physical IPV. This means that teaching women to pursue relationships that will promote and cultivate the fulfilment of the three SDT needs may prevent them from being vulnerable and may also enable them to live healthier lives. Furthermore, the sample size was relatively small and women were recruited through IYA; therefore our sample may not be representative of all rural, poor women in the Eastern Cape or South Africa. Also, our measures relied on self-report on sensitive information about sexually related issues and participants may have provided responses that are perceived to be socially desirable. However, efforts were made by our research team to encourage honest responses from the participants. Finally, we designed a crosssectional study, which may not have fully captured the hypothesized effects of the three needs on IPV. Therefore a longitudinal study may be a better design for capturing these relationships. Aside from the limitations of our investigation, this work highlights that it is important to identify new psychosocial determinants of intimate partner violence because it is a complex and persisting problem. This way identified correlates can help in 
the formulation of new change objectives for interventions to reduce women's exposure to IPV.

\section{Acknowledgements}

The manuscript preparation activities (towards a $\mathrm{PhD}$ dissertation) from which this study emanates was funded by the Medical Research Council of South Africa in terms of the National Health Scholars Programme from funds provided for this purpose by the Public Health Enhancement Fund. Additional funding (also towards a $\mathrm{PhD}$ dissertation) was also obtained from ZuidAfrikaHuis Studiefonds voor Zuid Afrikaans Studenten (SSF), The Netherlands. Dr Shegs James (Witwatersrand University, South Africa) provided guidance during the development, planning and data collection for this study. Mr Stefan Gruijters (Maastricht University) provided statistical input for the data analysis.

\section{Declaration of conflicting interests}

The authors declare that they have no competing interests.

\section{Funding}

The Ford Foundation (Grant \#11050509-0) funded the development and implementation of the study.

\section{Supplementary data accessibility}

Due to confidentiality agreements with research collaborators, supporting data can only be made available to bona fide researchers after a 6-month embargo period after publication has passed, and access is subject to a non-disclosure agreement. Details of the data and access requests can be made to the corresponding author. 


\section{References}

Abrahams, N., Devries, K., Watts, C., Pallitto, C., Petzold, M., Shamu, S., \& GarcíaMoreno, C. (2014). Worldwide prevalence of non-partner sexual violence: a systematic review. The Lancet, 383(9929), 1648-1654. doi:10.1016/S01406736(13)62243-6.

Abramsky, T., Watts, C. H., Garcia-Moreno, C., Devries, K., Kiss, L., Ellsberg, M., Heise, L. (2011). What factors are associated with recent intimate partner violence? Findings from the WHO multi-country study on women's health and domestic violence. BMC Public Health, 11(1), 109. doi: 10.1186/1471-2458-11-

109.

Albertyn, C. (2011). Law, gender and inequality in South Africa. Oxford Development Studies, 39(02), 139-162. doi: 10.1080/13600818.2011.568610.

Ali, P. A., \& Naylor, P. B. (2013). Intimate partner violence: A narrative review of the feminist, social and ecological explanations for its causation. Aggression and Violent Behavior, 18(6), 611-619. doi: 10.1016/j.avb.2013.07.009.

Baron, R. M., \& Kenny, D. A. (1986). The moderator-mediator variable distinction in social psychological research: Conceptual, strategic, and statistical considerations. Journal of personality and social psychology, 51(6), 1173-1182. doi:10.1037/0022-3514.51.6.1173.

Bell, K. M., \& Naugle, A. E. (2008). Intimate partner violence theoretical considerations: Moving towards a contextual framework. Clinical Psychology Review, 28(7), 1096-1107. doi: 10.1016/j.cpr.2008.03.003

Bentler, P. M. (1990). Comparative fit indexes in structural models. Psychological Bulletin, 107(2), 238. doi: 10.1037/0033-2909.107.2.238. 
Bill of rights, South Africa; Section 9(4). (1996). Certification of the Constitution of the Republic of South Africa, 1996 SA 744, BCLR 1253 Constitutional Court. Retrieved from http://www.justice.gov.za/legislation/constitution.

Brafford, L.J and Beck, K.H. (1991). Development and validation of a condom selfefficacy scale for college students. Journal of American College Health, 39(5): 219-225. doi: 10.1080/07448481.1991.9936238.

Brookings, J. B., \& Bolton, B. (1988). Confirmatory factor analysis of the interpersonal support evaluation list. American Journal of Community Psychology, 16(1), 137147. doi: 10.1007/BF00906076.

Brown, T. A. (2015). Confirmatory factor analysis for applied research. Guilford Publications. Retrieved from http://www.researchgate.net/publication/251573889

Byrne, B. M., \& Stewart, S. M. (2006). Teacher's corner: The MACS approach to testing for multigroup invariance of a second-order structure: A walk through the process. Structural Equation Modeling, 13(2), 287-321. doi:10.1207/s15328007sem1302.

Cavanaugh, C. E., Hansen, N. B., \& Sullivan, T. P. (2010). HIV sexual risk behavior among low-income women experiencing intimate partner violence: the role of posttraumatic stress disorder. AIDS and Behavior, 14(2), 318-327. doi:

0.1007/s10461-009-9623-1.

Chirkov, V., Ryan, R. M., Kim, Y., \& Kaplan, U. (2003). Differentiating autonomy from individualism and independence: a self-determination theory perspective on internalization of cultural orientations and well-being. Journal of personality and social psychology, 84(1), 97. 
Cohen, J. (1988). Set correlation and contingency tables. Applied Psychological Measurement, 12(4), 425-434. doi: 10.1177/014662168801200410.

Coker, A. L., Smith, P. H., Thompson, M. P., McKeown, R. E., Bethea, L., \& Davis, K. E. (2002). Social support protects against the negative effects of partner violence on mental health. Journal of Women's Health \& Gender-Based Medicine, 11(5), 465-476. doi: 10.1089/15246090260137644

Decker, M. R., Miller, E., McCauley, H. L., Tancredi, D. J., Anderson, H., Levenson, R. R., \& Silverman, J. G. (2014). Recent partner violence and sexual and drugrelated STI/HIV risk among adolescent and young adult women attending family planning clinics. Sexually Transmitted Infections, 90(2), 145-149. doi: doi:10.1136/sextrans-2013-051288.

DePadilla, L., Windle, M., Wingood, G., Cooper, H., \& DiClemente, R. (2011). Condom use among young women: modeling the theory of gender and power. Health Psychology 30(3), 310-319. doi: 10.1037/a0022871

Devries, K. M., Mak, J. Y., García-Moreno, C., Petzold, M., Child, J. C., Falder, G., \& Watts, C. H. (2013). The global prevalence of intimate partner violence against women. Science, 340(6140), 1527-1528. doi: 10.1126/science.1240937.

Dunkle, K. L., Jewkes, R. K., Brown, H. C., Gray, G. E., McIntryre, J. A., \& Harlow, S. D. (2004). Gender-based violence, relationship power, and risk of HIV infection in women attending antenatal clinics in South Africa. The Lancet, 363(9419), 1415-1421. doi: 10.1016/S0140-6736(04)16098-4.

Domestic Violenec Act116. (1998). Certification of the Constitution of the Republic of South Africa, 1998 SA 744, BCLR 1253 Constitutional Court. Retrieved from 
http://www.wlce.co.za/index.php/2013-04-30-11-53-09/2013-05-08-11-48-

14/violence-agains-women/309-a-simplified-guide-to-the-violence-act.

Gass, J. D., Stein, D. J., Williams, D. R., \& Seedat, S. (2011). Gender differences in risk for intimate partner violence among South African adults. Journal of Interpersonal Violence, 26(14), 2764-2789. 10.1177/0886260510390960.

Gibbs, A., Sikweyiya, Y., \& Jewkes, R. (2014). “Men value their dignity”: securing respect and identity construction in urban informal settlements in South Africa. Global Health Action, 7. doi:10.3402/gha.v7.23676.

Grose, R. G., \& Grabe, S. (2014). The Explanatory Role of Relationship Power and Control in Domestic Violence Against Women in Nicaragua A Feminist Psychology Analysis. Violence against Women, 20(8), 972-993. doi: 10.1177/1077801214546231.

Hu, L., \& Bentler, P. M. (1999). Cutoff criteria for fit indexes in covariance structure analysis: Conventional criteria versus new alternatives. Structural Equation Modeling: A Multidisciplinary Journal, 6(1), 1-55. doi: 10.1080/10705519909540118.

Jackson, D. L. (2001). Sample size and number of parameter estimates in maximum likelihood confirmatory factor analysis: A Monte Carlo investigation. Structural Equation Modeling, 8(2), 205-223. doi: 10.1207/S15328007SEM0802_3.

Jewkes, R. (2002). Intimate partner violence: causes and prevention. The Lancet, 359(9315), 1423-1429. doi:10.1016/S0140-6736(02)08357-5.

Jewkes, R. K., Dunkle, K., Nduna, M., \& Shai, N. (2010). Intimate partner violence, relationship power inequity, and incidence of HIV infection in young women in 
South Africa: a cohort study. The Lancet, 376(9734), 41-48. doi:10.1016/S01406736(10)60548-X.

Karamagi, C. A. S., Tumwine, J. K., Tylleskar, T., \& Heggenhougen, K. (2006). Intimate partner violence against women in eastern Uganda: implications for HIV prevention. BMC Public Health, 6(1), 284. doi: doi:10.1186/1471-2458-6-284.

Kim, J. C., Watts, C. H., Hargreaves, J. R., Ndhlovu, L. X., Phetla, G., Morison, L. A., Pronyk, P. (2007). Understanding the impact of a microfinance-based intervention on women's empowerment and the reduction of intimate partner violence in South Africa. American Journal of Public Health, 97(10), 1794-1802. doi: 10.2105/AJPH.2006.095521.

Koenig, M. A., Ahmed, S., Hossain, M. B., \& Mozumder, A. B. M. K. A. (2003). Women's status and domestic violence in rural Bangladesh: individual-and community-level effects. Demography, 40(2), 269-288. Retrieved from http://www.jstor.org/stable/3180801

Meintjes, S. (2003). The politics of engagement: Women transforming the policy process-domestic violence legislation in South Africa. No Shortcuts to Power. African Women in Politics and Policy Making (pp. 140-159). London, England: Zed Books.

Minnis, A. M., Doherty, I. A., Kline, T. L., Zule, W. A., Myers, B., Carney, T., \& Wechsberg, W. M. (2015). Relationship power, communication, and violence among couples: results of a cluster-randomized HIV prevention study in a South African township. International Journal of Women's Health, 7, 517. doi: 10.2147/IJWH.S77398. 
Mogale, R. S., Burns, K. K., \& Richter, S. (2012). Violence Against Women in South Africa Policy Position and Recommendations. Violence against Women, 18(5), 580-594. doi: 10.1177/1077801212453430.

Morrell, R., Jewkes, R., \& Lindegger, G. (2012). Hegemonic masculinity/masculinities in South Africa: Culture, power, and gender politics. Men and Masculinities, 1097184X12438001. doi: 10.1177/1097184X12438001.

Mpondo, F., Ruiter R.A., van den Borne., \& Reddy P.S. (2015). Self-determination and gender-power relations as predictors of condom use self-efficacy among South African women. Health Psychology Open. 2(2). 20551029155598876.

Muthén, L. K., \& Muthén, B. O. (2013). Mplus 7.11. Los Angeles, CA: Muthén \& Muthén. Retrieved from https://www.statmodel.com.

Nanda, G. (2011) Compendium of Gender Scales. Washington, DC: FHI 360. Retrieved from https://www.c-changeprogram.org/content/gender-scales-compendium.

Ng, J. Y. Y., Ntoumanis, N., Thøgersen-Ntoumani, C., Deci, E. L., Ryan, R. M., Duda, J. L., \& Williams, G. C. (2012). Self-determination theory applied to health contexts a meta-analysis. Perspectives on Psychological Science, 7(4), 325-340. doi: doi: 10.1177/1745691612447309.

Ogland, E. G., Xu, X., Bartkowski, J. P., \& Ogland, C. P. (2014). Intimate Partner Violence Against Married Women in Uganda. Journal of Family Violence, 29(8), 869-879. doi: 10.1007/s10896-014-9640-3.

Patrick, H., Knee, C. R., Canevello, A., \& Lonsbary, C. (2007). The role of need fulfillment in relationship functioning and well-being: a self-determination theory 
perspective. Journal of Personality and Social Psychology, 92(3), 434. doi:10.1037/0022-3514.92.3.434.

Pettifor, A., MacPhail, C., Anderson, A. D., \& Maman, S. (2012). ‘If I buy the Kellogg’s then he should [buy] the milk': young women's perspectives on relationship dynamics, gender power and HIV risk in Johannesburg, South Africa. Culture, Health \& Sexuality, 14(5), 477-490. doi:10.1080/13691058.2012.667575

Russell, M., Cupp, P. K., Jewkes, R. K., Gevers, A., Mathews, C., LeFleur-Bellerose, C., \& Small, J. (2014). Intimate partner violence among adolescents in Cape Town, South Africa. Prevention Science, 15(3), 283-295. doi:10.1007/s11121-013-0405-7.

Seedat, M., Van Niekerk, A., Jewkes, R., Suffla, S., \& Ratele, K. (2009). Violence and injuries in South Africa: prioritising an agenda for prevention. The Lancet, 374(9694), 1011-1022. doi:10.1016/S0140-6736(09)60948-X.

Shai, N. J., \& Sikweyiya, Y. (2015). Programmes for change: Addressing sexual and intimate partner violence in South Africa. SA Crime Quarterly, (51), 31-41. doi: http://dx.doi.org/10.4314/sacq.v51i1.4.

Shefer, T., Crawford, M., Strebel, A., Simbayi, L. C., Dwadwa-Henda, N., Cloete, A., Kalichman, S. C. (2008). Gender, power and resistance to change among two communities in the Western Cape, South Africa. Feminism \& Psychology, 18(2), 157-182. doi: 10.1177/0959353507088265.

Sheldon, K. M., Ryan, R., \& Reis, H. T. (1996). What makes for a good day? Competence and autonomy in the day and in the person. Personality and Social 
Psychology Bulletin, 22, 1270-1279.

http://www.researchgate.net/profile/Richard_Ryan2/publication/228079272

Silva, M. N., Marques, M. M., \& Teixeira, P. J. (2014). Testing theory in practice: The example of self-determination theory-based interventions. European Health Psychologist, 16(5), 171-180. Retrieved from www.openhealthpsychology.com

Steiger, J. H. (1990). Structural model evaluation and modification: An interval estimation approach. Multivariate Behavioral Research, 25(2), 173-180. Retrieved from http://www.statpower.net/Steiger\%20Biblio/Steiger90b.pdf

Stöckl, H., Devries, K., \& Watts, C. (2015). The epidemiology of intimate partner violence. In P. D. Donnelly \& C. L. Ward (Eds), Oxford Textbook of Violence Prevention: Epidemiology, Evidence, and Policy (pp. 43-48). Oxford, UK: Oxford University Press.

van Niekerk, T. J., \& Boonzaier, F. A. (2016). "The Only Solution There Is To Fight” Discourses of Masculinity Among South African Domestically Violent Men. Violence against women, 22, 271-291. doi:1077801214555473.

Walker, S., \& Barton, L. (2013). Gender, Class and Education (Routledge Revivals). Routledge.

Weinstein, N., \& Ryan, R. M. (2011). A self- determination theory approach to understanding stress incursion and responses. Stress and Health, 27(1), 4-17. doi: 10.1002/smi.1368 